\title{
Climate Variability Impact and Adaptation: The Experience of Maize Farmers in Bui Division, Northwest Cameroon
}

\author{
Kiming Ignatius Ngala ${ }^{1, *}$, Godwill Tobouah Nyanchi ${ }^{1}$, Moye Eric Kongnso ${ }^{2}$, \\ Nkiene Valery Antu ${ }^{1}$, Nghobuoche Frankline ${ }^{1} \&$ Mor Noel Muala ${ }^{3}$
}

\footnotetext{
${ }^{1}$ Department of Geography, Faculty of Arts, Letters and Social Sciences, University of Yaoundé, Cameroon ${ }^{2}$ Department of Geography, Faculty of Arts, Letters and Social Sciences, University of Dschang, Cameroon ${ }^{3}$ Department of Business Administration, Cyprus International University, Nicosia

*Corresponding Author: ignatiusngalakiming@gmail.com
}

\begin{abstract}
This study examines the impact of climate variability on maize (Zea mays) production in Bui Division and adaptation mechanisms employed by maize famers. The guiding premise is that climate variability has created unusual environmental conditions, partly responsible for the drop in the yields of maize, in Bui, where famers adaptation options remain inefficient. A mixed approach was used in generating data from both primary and secondary sources. Questionnaires were administered to 180 purposively selected maize farmers with at least 20years of experience in maize cultivation and interviews carried with 24 key informants. Secondary data was collected from the divisional office in charge of agricultural statistics and surveys for Bui. Data was analysed both qualitatively and quantitatively. Results revealed that annual rainfall witnessed a slight decrease in amount between 1991 and 2010, erratic events, frequent dry spells, decrease in rainy days and fluctuations in the onset and termination of the rainy season, while temperature witnessed a moderate rising trend. These varying trends in temperature and rainfall across Bui were observed to have partly contributed to an average decrease of $200 \mathrm{~kg} / \mathrm{ha}$ in maize yields between 2000 and 2010. The strategies adopted by farmers to face the negative effect of varying climatic elements proved inefficient. For proper adaptation, government should develop efficient meteorological systems through which information on weather predictions will be disseminated to farmers, provide agricultural loans and build farmers' capacity on the best adaptation options, with focus on youths, known to have the defining attributes when it comes to modern agriculture.
\end{abstract}

Keywords-Adaptation, Climate Variability, Impact, Maize production.

\section{INTRODUCTION}

Food crop production remains one of the principal agricultural activities in Cameroon, with maize (Zea mays L.) being one of the dominantly cultivated grain crop across the national territory. Apart from being a source of staple food for a good number of village communities especially in the Northwest and Western parts of the country, it also provides food for animals and serves as a raw material for a number of industries, especially the brewery industry. In terms of quantity, maize production in Cameroon increased from 263 tons in 1970 to 2,100 tons in 2019, growing at an average annual rate of $5.84 \%$ (World Data Atlas, 2020). However, climate change through its oscillations in the local climatic elements especially rainfall and temperature, has been threatening maize production in Sub Saharan Africa thereby risking food security especially as it is rain-fed in these countries (Mulungu \& Ng'ombe, 2019). Despite technological advances such as improved crop varieties, irrigation systems and use of pesticides, weather is still a key factor in food crop production and its effects are related to 
the variability in local climates rather than to global climatic patterns (IPCC 2001).

Estimates show that between present time and 2050, global temperatures will increase by $30 \mathrm{C}$ while sea level shall rise by $85 \mathrm{~cm}$ (World Meteorological Organisation, 1990) should the trend continue. Globally, climate change is manifesting itself through extreme climatic events and disruption of the normal climatic patterns in many parts of the world. The general cause attributed to these variations is the accumulation of greenhouse gases in the atmosphere. The international struggle to reach a binding deal on cutting down greenhouse gas emissions has is yet to yield any positive results, making the trend one of much greater worry. Climate change has become the focal point of most global deliberations due to its impact on various biophysical systems which disturb prime sources of food and water, through droughts, temperature surges and variable rainfall among others (Bendell, 2019). In the tropical world, poor farmers are the most affected since a majority of the population is neither prepared to combat the situation, nor capable of repairing the damage.

Majority of smallholder farmers in Africa are unable to adapt to the changing climatic trends due to low levels of technology, scarcity of financial resources and inability to access climate change related information. Developing climate change adaptive capacities that are focused on rural African milieus has lots of constraints especially in areas where majority of farmers are financially weak. (Ringler,2008). Switching to fast-maturing varieties, planting a minimum of two crops at a time, mixing cereals with pulses and tubers, and relay-cropping through the rainy season are effective means of ensuring at least some harvest during climatic fluctuations (Nangoma \& Sonja, 2008). There have been reports of disruption of the agricultural calendar in many parts of Cameroon resulting from extreme climatic events and the resulting effects are plant stress and fluctuations in farmers' output, negatively affecting food insecurity in the Central African sub region. Bui Division which is located on a dominantly hilly environment with more than three quarter of its population engaged in food crop production, lack modern farm tools, basic inputs and efficient storage facilities, will possibly not be exempted. Majority of peasant farmers in Bui Division, are economically weak, Unfortunately, unexpected climatic events within the locality of Bui are likely to affect maize yields, especially as its production is mainly rain-fed.
The prime problem of this study is that, maize production is directly reflected in long term climatic variations. Maize, which is the dominant food crop in Bui Division, rapidly shows signs of wilting in periods of extreme temperature conditions. There have been disruptions in the agricultural calendar, attributed directly or indirectly to man induced climate change that alters the composition of the global atmosphere, added to natural climate variability observed over comparable time periods. This paper has as objectives the following (1) ascertain whether there has been any variability in temperature and rainfall in Bui Division between 1991 and 2010, (2) evaluate the effects of climate variability on maize production, (3) examine the strategies put in place by maize farmers to adapt to the negative effects of climate variability.

\section{MATERIALS AND METHODS}

\section{1: Profile of the Study area}

Bui Division is located between latitude $6^{\circ} 00^{\prime \prime}$ to $6^{\circ} 20^{\prime \prime}$ North of the Equator and longitude $10^{\circ} 30^{\prime \prime}$ to $10^{\circ} 60^{\prime \prime}$ East of the Greenwich Meridian. It is a huge orographic plateau and part of the Bamenda highlands of the Cameroon Volcanic Line. It hosts the second highest peak (Mount Oku, $3011 \mathrm{~m}$ above sea level) in West Africa, and lies in a Southwest to Northeast direction (Hawkins and Brunt, 1963). The areas contain a major section of the Mbaw-Tikar Plains (about $900 \mathrm{~m}$ above sea level), (Tume, 2008). The entire division has a total surface area of $2,795 \mathrm{~km} 2$ (Divisional Delegation of lands, Bui). It is bounded to the North by Donga -Mantung Division, East by Mentchum, North East by Boyo, Southwest by the Noun Division in the West Region, and to the South East by the Ngoketunjia Division(Fig1). The climate is generally similar to that of most localities within the Northwest Region, though the mountainous nature of the region slightly alters the pattern. The combination of altitude, temperature inversion, slope orientation, mist and clouds leads to the existence of micro scale climatic differentials. Bui has two marked seasons, rainy season (mid-March to mid-November) and the dry season covers the rest of the period. The soils have mostly shallow profiles and nutrient rich tops, with lateritic characteristics underneath. Infertile lateritic soils are observed mostly on steep slopes with high rates of rain triggered erosion while pockets of alluvial soils are common along flood plains. Fig1 present the location map of the study area. 


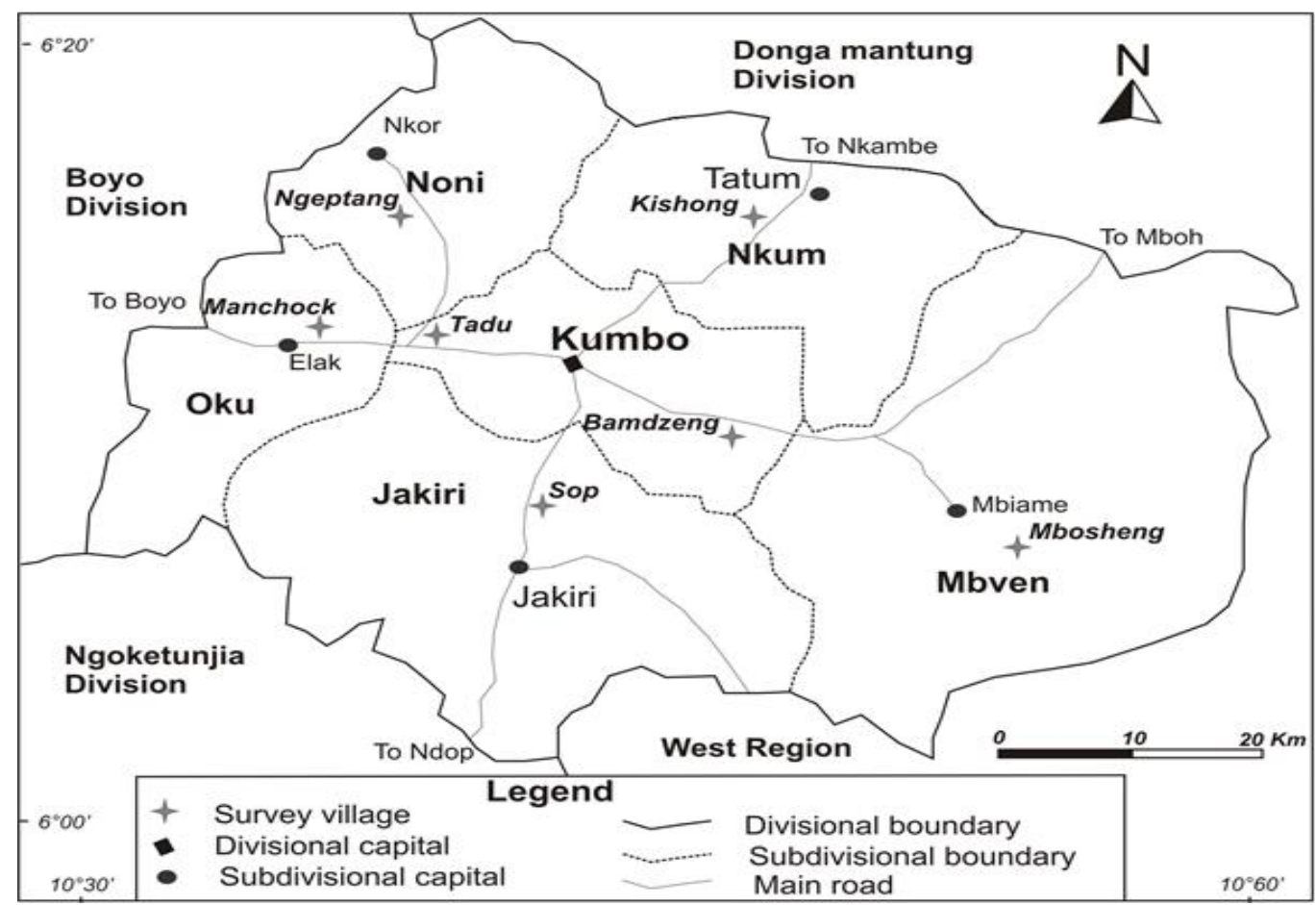

Fig.1: Location of Bui Division

Source: Administrative map of Cameroon

\section{2: Data Description}

The parameters investigated were rainfall and temperature, known to have a determinant role in the development and productivity of the maize plant. The data covered a time scope of 20 years (1991 to 2010). Data came from Bui delegation of agriculture, Banso Baptist hospital(BBH) and TAMSAT (Tropical Application of Meteorology using Satellite) website. Some reference material provided before 1991 was also consulted which helped give an in-depth analysis and ease the understanding of the issues at stake. Data on maize comprised of yearly harvests, surface area cultivated (2000-2010) and perceptions of farmers on climate variability and change and its impact. This came from the divisional office for agricultural statistics and surveys and maize farmers of Bui division.

\section{3: Data collection, treatment and analysis}

A cross sectional approach was used, in collecting data from randomly selected maize farmers with at least a 20years longevity in maize cultivation alongside some key informants. A total of 180 questionnaires were administered in the seven selected sites across Bui, based on maize farmer population. Meteorological data obtained from the department of agricultural statistics and surveys and from the BBH weather archives. The questionnaires were administered on spot, while Focus Group Discussions (FGDs) with six maize farmer's groups and eighteen interviews with some stake holders in the sector ascertained some of the field observations. The selection of participants for group discussions ensured a balance in gender, age and geographical dispersion in the target area. Expertise was borrowed from the agricultural extension service for Bui, to facilitate the field observation phase. This further helped establish a typology of adaptation strategies put in place and their constraints. Data from the questionnaires was analysed both qualitatively and quantitatively. MS Excel, Statistical Package for Social Sciences (SPSS), version 20.0 were used in the analysis of data. Content analysis helped in exploiting results from Focus group discussions. Descriptive tools used were; the mean, standard deviation and coefficient of variation, and to establish rainfall and temperature trends, data was smoothened using 3years running means. The cumulative difference and the cumulative percentile difference (CPD) were calculated to establish temperature and rainfall anomalies. These then gave the baseline from which anomalous climatic situations and the degree of 
variability and reliability in temperature and rainfall were determined. To determine trends in temperature and rainfall, regression lines were fitted to the data to establish the trend direction of each climatic element. The calculated R-square $\left(\mathrm{R}^{2}\right)$ value for each analysis helped in determining the significance of the trend. Pearson Product Moment Correlation Coefficient, usually referred to as Pearson's ' $r$ ' was used (' $r$ ' is the statistical notation we used to report this correlation coefficient).

\section{RESULTS}

3.1: The State of maize production, farmers and farming characteristics in Bui

Maize stands to be the main leading food crop produced in Bui, given the fact that corn-fufu and huckleberry remains the main staple food in the area. The fresh grains are eaten roasted or boiled on the cob, dry grains are popped, It's also used to produce "corn beer", known locally as "nkaang" or "Shah" depending on the alcoholic content. Local varieties can be distinguished by grain colour and growth height, with most of the farm sizes ranging between 0.5 to 0.8 hectares. Field survey revealed $30 \%$ of the farmers produce white maize only, $62 \%$ produce both yellow and white while $8 \%$ produce yellow only, with farm tools still predominantly rudimentary. Farmers' educational level was noted to be generally low, more than $57 \%$ had completed primary education, $24 \%$ for secondary education, higher education $10 \%$, while $9 \%$ had never gone to school. The major proportion of the farmers (46\%) are above 40years of age, $39 \%$ between 30 and 40years, with just $15 \%$ below 30years. The low engagement of youths in maize production is this area is partly explained by the high rate of rural exodus observed within Bui in recent decades. The use bush fire to do away with the grass in the farm in order to ease the hoeing process and reduce labour cost, is still common around the Noni zone, where arable land is still in relative abundance. Such acts kill soil organisms while increasing the concentration of atmospheric $\mathrm{CO}_{2}$, a major greenhouse gas. The most common method of farm preparation involves the burying weeds in the ground during ridge formation, which helps enrich the soil. Maize cultivation here is greatly controlled by climatic alternations while differences exist in the timing of farm preparation, tilling, weeding and harvesting due to significant topographic variations over very short distances.

Temperature and rainfall differentials with altitude, make maize harvesting span over a long period of time. Planting is done, mostly in a mixed cropping system, with backyard crops such as groundnuts, beans and Irish potatoes, depending on farm location. Weeding observed to generally begin by mid-April, appeared to be the busiest period for maize farmers. Despite the fact that maize is planted within the same one or two weeks' period across the entire region, lower altitude areas (800-1000m above sea level) with relatively high temperatures such as Nkor, Lasin, Ngeptang, Lip, Ber, Ber, Tan, Mbockam, Gwarkang, Ibal and Mbam Oku, begin harvesting as early as July while in areas situated as from $1800 \mathrm{~m}$ above sea level such as Tadu, Mbockenghas, Rifem, Simonkoh, Manchock, Ngvenkei II and Ibalichim, harvest begins as from September, giving a two months' difference.

The relative high temperatures in the low altitude zones permit the maize to receive the required heat units for development and maturity (Growing degree days or units) within a comparatively short period of time. This explains why the period between sowing and maturity for the maize plant generally increases with altitude. Field survey revealed that the farmers generally lack both farm inputs and basic household needs. In order to ensure a continuous food supply for the home and the availability of planting seeds, adequate preservation techniques are of high necessity. The popular traditional techniques of maize preservation in the area was observed to have been disappearing gradually. Such is the case of the skillfully constructed cribs (a small hut-like structure without walls, with a ceiling and roof supported by strong pillars of about 2 meters high) which allows for the free circulation of air that had a drying and cooling effect which prevents weevils from destroying the maize. Today in Bui, even the locally constructed granaries for maize storage are hard to find. Farmers explained that with a general fall in maize yields over time in the region, most farmers easily take home their produce, immediately after harvest. Fig2 shows variation in maize yield and cultivated area. 


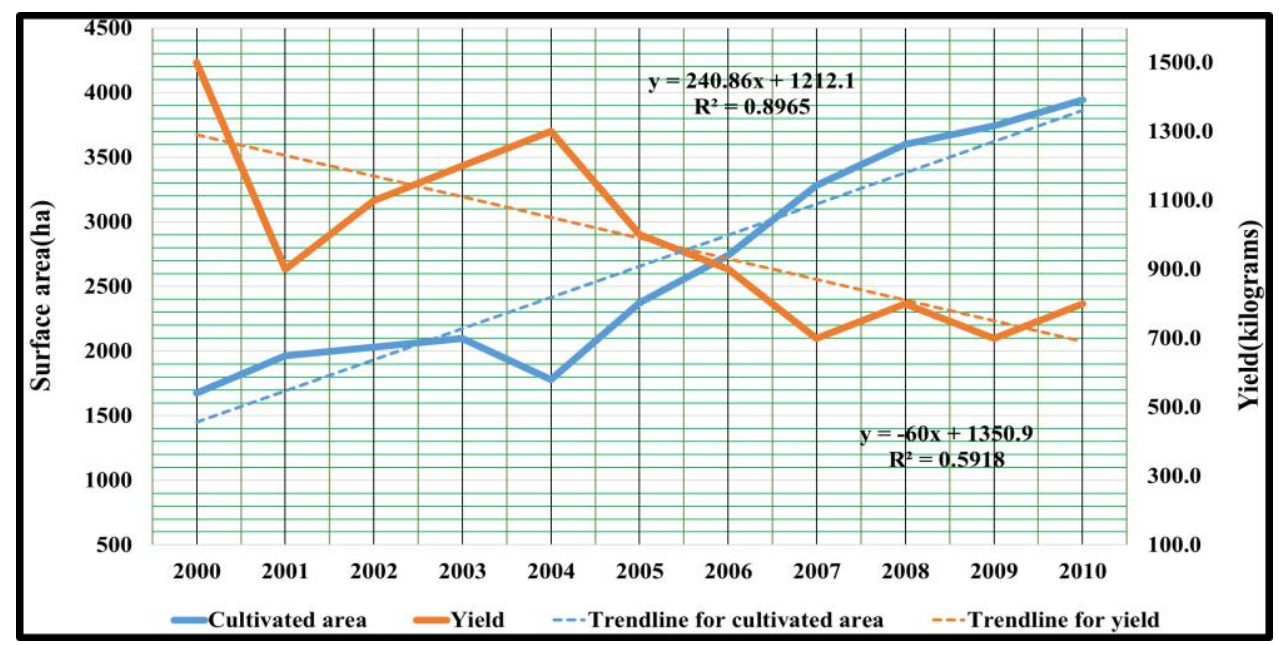

Fig.2: Evolution in maize yield and cultivated area in Bui division, 2000-2010

Source: Author's construct using data from Bui delegation of agriculture (2018))

From Fig2 it can be noted that after the year 2000, the next year witnessed a slight drop in maize yield, followed by a rising trend in yield up to 2004 , after which a sharp drop is observed in the two production seasons that followed. The last four years of the period registered a relatively stable but fluctuating trend in yields while output was noted to have increased over the period. The cultivated surface area for maize show an almost steady increase throughout the period, except for the year 2004 where there is a visible drop. The decreasing yield and expanding cultivated area over time is further confirmed by the trend line equation where the cultivated area has a positive gradient value 240.8 at a sloping angle of 0.897 while yields have a negative gradient value of -60.0 with a sloping angel of 0.592 . This was corroborated by the opinions of farmers on the trends of these two elements in Bui, between 1991 and 2010. Up to $53 \%$ of the farmers indicated their yields have generally been decreasing over the years, $21 \%$ said theirs were increasing while $26 \%$ indicted their yields have been stable over the period. The general observation across Bui shows there have been significant changes in maize production in the area, determined by factors which range from the type of maize seeds, prevailing climatic conditions, cultivated area, soil degradation and farm inputs. Maize was reported to yield most where it is cultivated mainly in a sole cropping system, such as in Wasi-Ber and Mbonso areas.

3.2: The variability and reliability of the key climatic elements

Examining climatic variability on monthly, seasonal, annual and decadal scales over the period was of crucial importance, especially in the tropical environment where major climatic dynamics take place over relatively shorter periods. The calculated standard deviation $(\sigma)$, coefficient of variation (CV) years running means and cumulative percentiles helped established the trends for both temperature and rainfall over the period. The variation in these elements have been affecting some physiological processes in maize, soil characteristics and consequently crop yield. Fig3 presents an Isothermal map for both Bui division, realized based on TAMSAT data. 


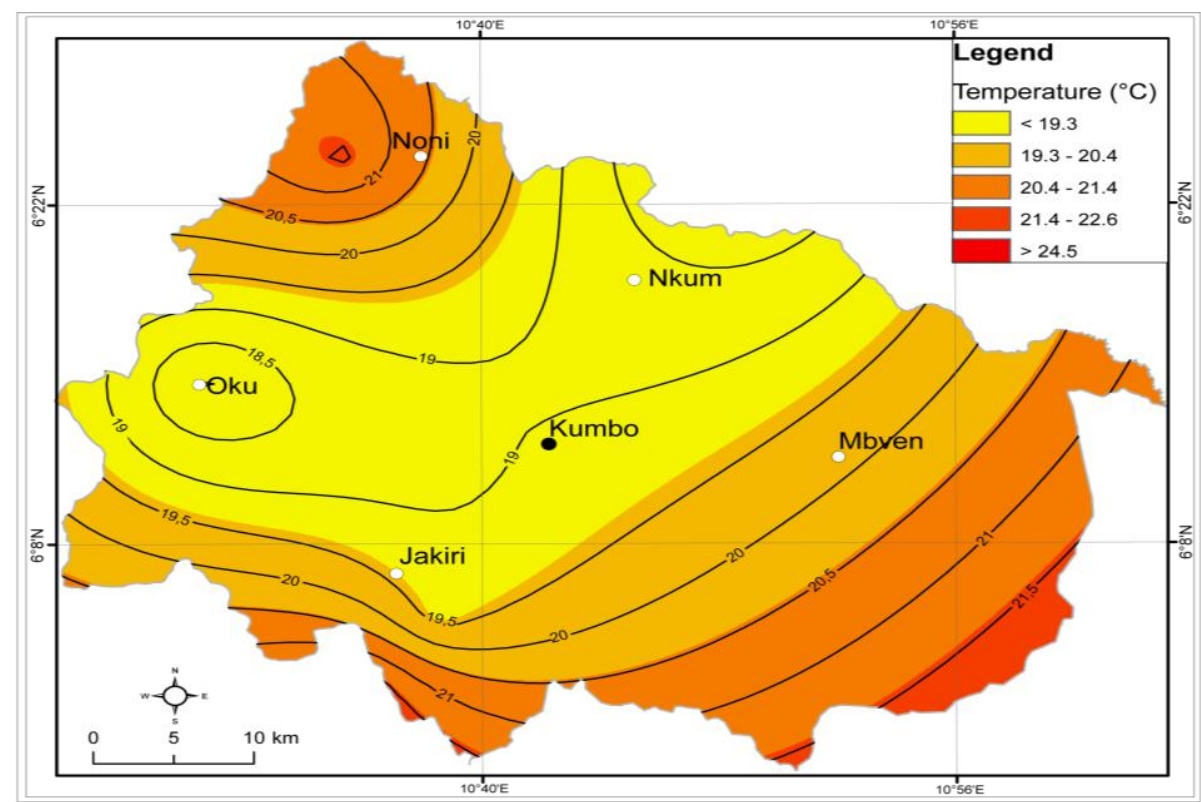

Fig.3: An Isothermal map of Bui Division

Source: Authors realization using data from TAMSAT (2020)

From Fig3, it can be observed that mean temperature in Bui varies slightly across the area, with relatively higher figures in the Southeast (Wasi-Ber and Mbonso) and Northwestern (Bamti and Nkor and Lasin) parts of the division. This mean also observed to be decreasing as you move towards the higher altitudes zones of Simonkoh-Oku and Rifem in Mbiame. There is more to say about temperature variation in Bui between 1991-2010, from the analysis of ground data.
Variations and variability in temperature are expected to affect the rate of evapo-transpiration, soil moisture levels, germination, vegetative development, flowering and the entire photosynthetic process. When the optimal range of temperature values for maize is exceeded, it tends to respond negatively. All these manifestations will have varying consequences on both the output and yield of maize. See Fig4 for evolution in mean temperature trend.

\subsection{1: Variation and variability in temperature and} anomalies

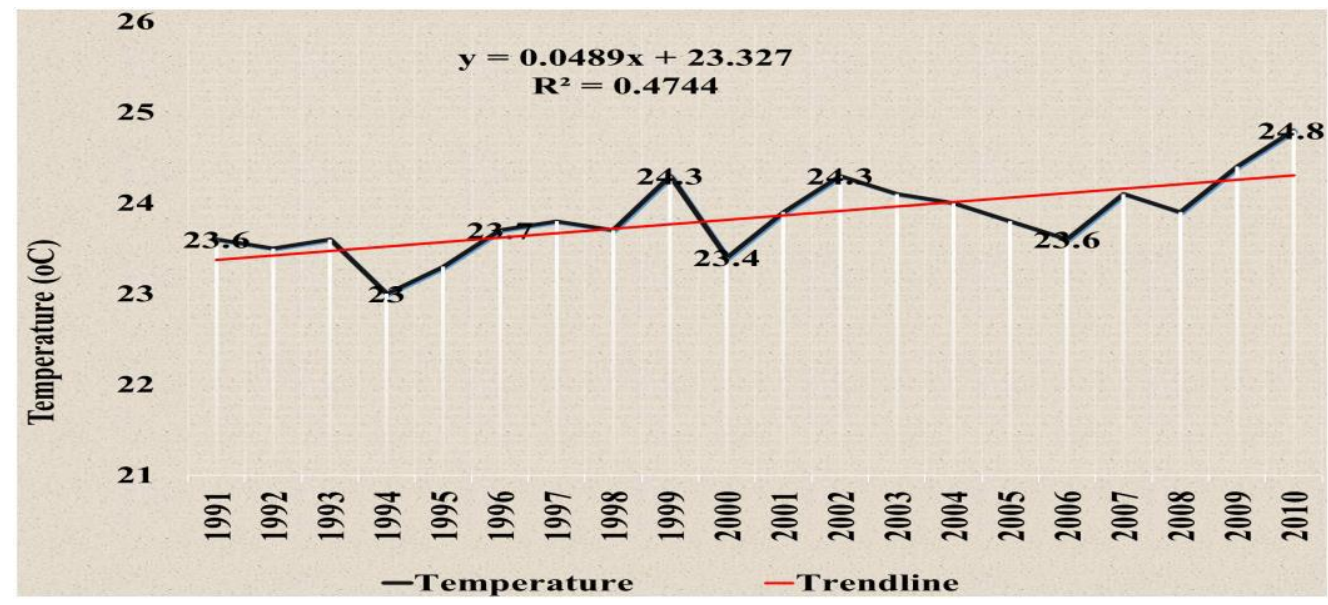

Fig.4: Evolution in mean annual temperature in Bui Division, 1991-2010

Source: Author's construct using data from Bui delegation of agriculture and BBH (2018) 
From Fig4, mean annual temperature show visible variations throughout the period, with a slight decrease between 2002 and 2006. The years 1994 registered the lowest mean temperature over the period while 2010 hard the warmest temperature. From figure evidence it can be

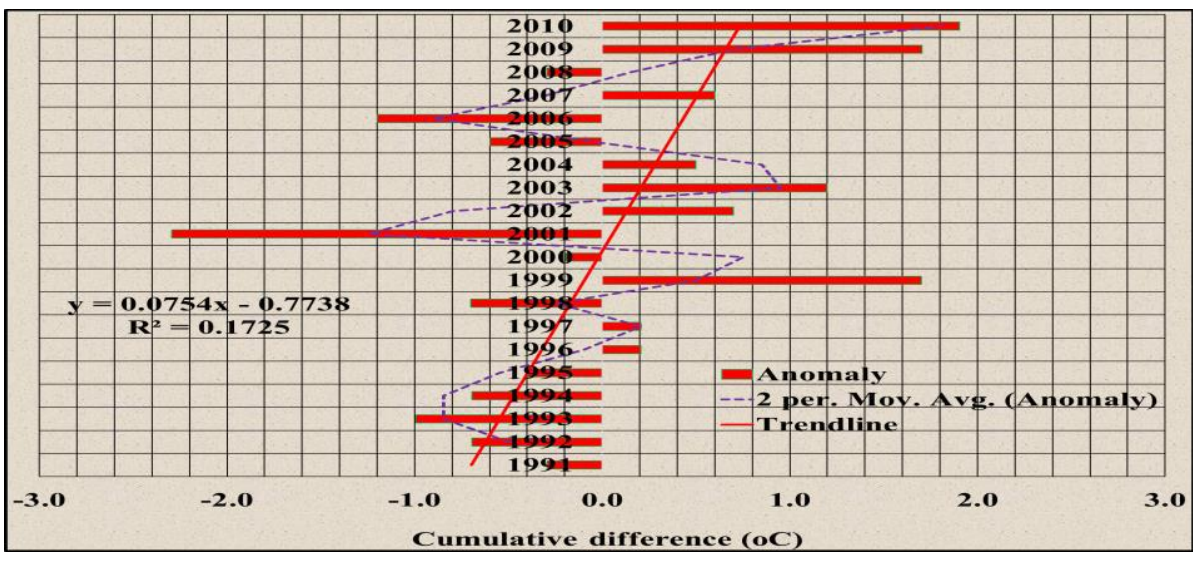

Fig.5: Inter-annual variation in temperature anomalies in Bui Division,1991-2010

Source: Author's construct using data from Bui delegation of agriculture and BBH (2018)

Analysis of meteorological data revealed varying anomalous situations for temperature over the period (Fig5). The first five years of the periods show evidence of moderate temperature, with negative anomalies that hardly went beyond $-1{ }^{\circ} \mathrm{C}$.The years 1996 and 97 also show signs of stability, with 1999 registering the greatest positive anomaly for the decade $1991-200\left(+1.7^{\circ} \mathrm{C}\right)$, indicating a relatively warmer season for maize farmers. The coldest season for the period occurred in 2001 , with a deviation of $-2.3^{\circ} \mathrm{C}$, which could have likely caused delays in maize maturity. From 2002 right up to 2010, a dominance of positive anomalies observed that the decade 2001-2010 was relatively warmer than that for 1991-2000. The temperature rising fluctuating trend with a positive gradient value of 0.049 at a sloping angel of 0.474 . Temperature anomalies are presented on Fig5.

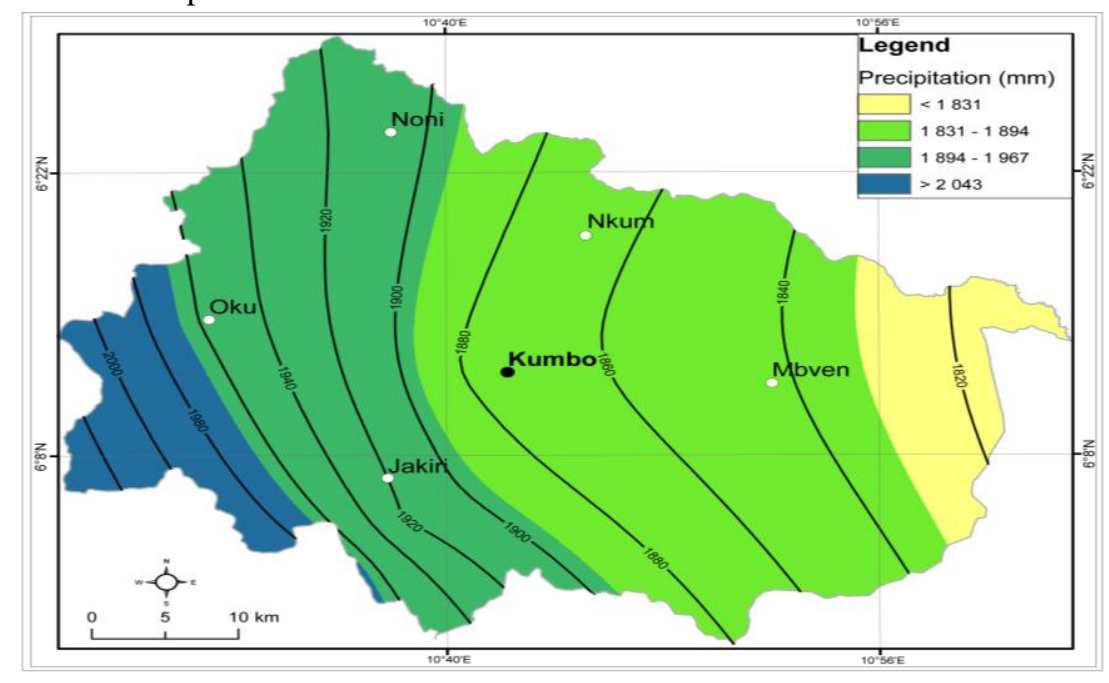

Fig.6: An Isohyetal map of Bui Division

Source: Authors realization, using data from TAMSAT (2020) 
T0 better comprehend the situation of rainfall variability in Bui, ground data analysis was of great importance. The annual rainfall amounts were smoothened using a three years running means to boost its reliability by either minimizing or neutralizing the effects of the errors committed during the collection of data (Fig7).

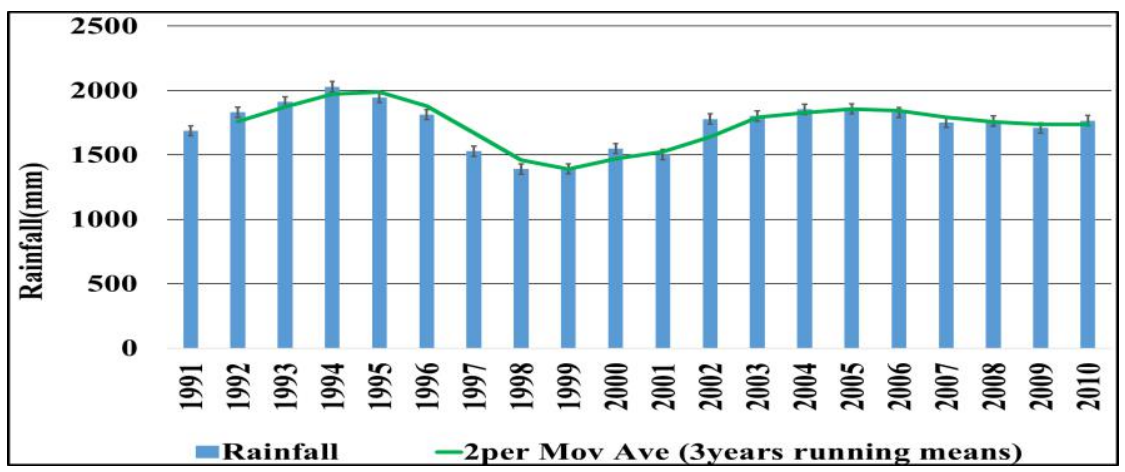

Fig.7: Smoothened annual rainfall amount for Bui Division, 1991-2010

Source: Author's construct using data from Bui delegation of agriculture and BBH (2018)

Evidence from Fig7 shows a slight increase in rainfall totals from 1991 up to 1994, and slight drop in the years that followed. The period 1998-2001 recorded the lowest amount of rainfall. Throughout the second decade of the period, annual rainfall hardly went above $2000 \mathrm{~mm}$, which was relatively more common during the period 19912000. There has been an overall slight decrease in rainfall amount in Bui over the study period, a consequence of the average decrease in rainy days from 179days between 19912000 to 149days between 2001-2010. The greatest rainfall intensity was registered in1996, where flooding risk and erosion level were relatively high while the year 2000 had the least intense rains for the period. The cumulative rainfall differences for the different years were used to demonstrate annual anomalies. The anomalous trends for annual rainfall are presented on Fig8.

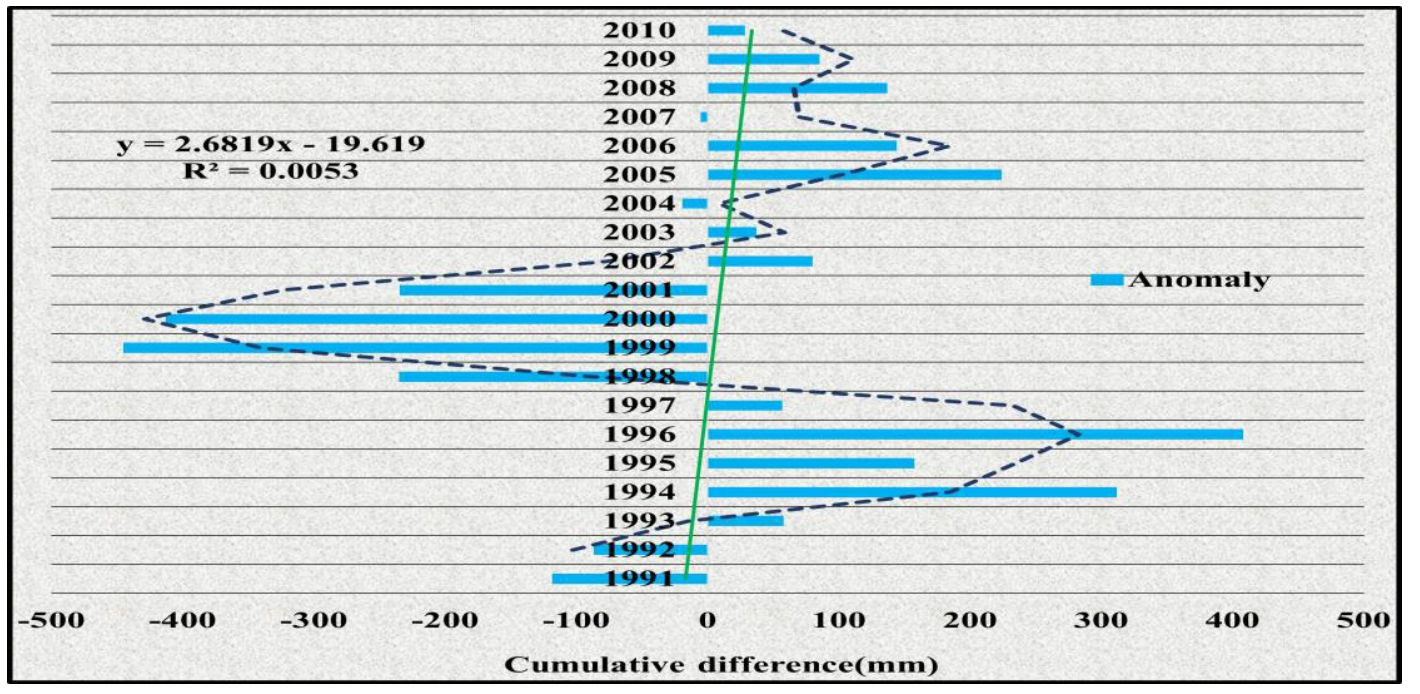

Fig.8: Inter-annual variation in rainfall anomalies in Bui Division, 1991-2010

Source: Author's construct using data from Bui delegation of agriculture and BBH (2018)

From Fig8, can be observed that the results of the analysis indicate occurrence of significant anomalies in Bui division between 1999 and 2010 which can be grouped into three periods. The first seven years recorded relatively high amounts of rainfall that most often went above the periodic mean. This was likely a more favourable period for maize cultivation in Bui depending on its seasonal distribution. The period 1998-2001 was characterized by both low rainfall amounts and poor distribution as shown by the high negative anomalies that went as high as $-400 \mathrm{~mm}$ in certain years. This wasn't a very favourable period for maize production in Bui, due to frequent dry spells and delays in the onset of the rainy 
season. The positive anomalies that characterized the last years are relatively low indicating a certain degree of stability, except for 2005 that had anomaly above $+200 \mathrm{~mm}$. However, there exist seasonal anomalies in the dry and wet season's rainfall (Fig9) These anomalies are known to also indicate the level of fluctuations in rainfall and occurrence of extreme rainfall events, which directly influence rainfall distribution and consequently maize output and yield.

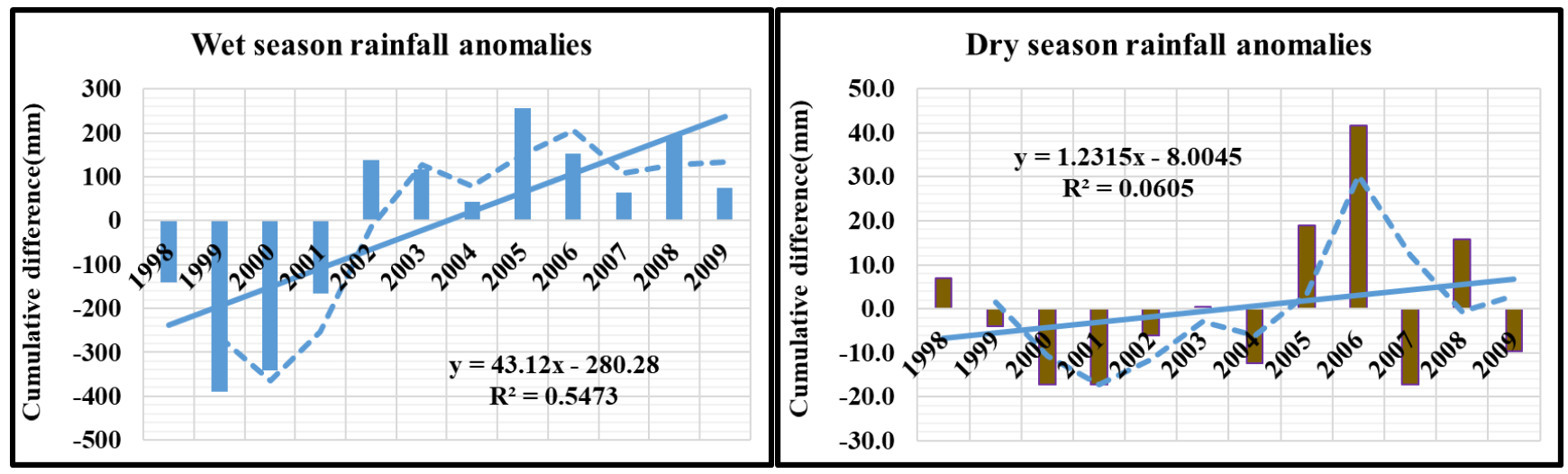

Fig.9: Wet and dry seasons rainfall amomalies for Bui division 1998-2009

Source: Author's construct using data from Bui delegation of agriculture and BBH (2018)

Seasonally, the anomalous rainfall events varried greatly between the wet and the dry seasons for the period1998-2009(Fig7). Field findings revealed that years with significant rainfall events during the dry season like the case of 2006 were followed with delays and scanty rains in the months of March and April, implying very challenging times for maize in the division. The wet season(March November) registered continous negative anomalies for four consecutive seasons(1998-2001), with years like 1999 registering a deviation of up to $-390 \mathrm{~mm}$. This was a consequence of the highly frequent dry spells that characterised the region during the last decade of the $20^{\text {th }}$ century, a major hindrance to the timely germination and vegetative development of the maize plant. The years 20022009 generally had abundant rains though with lots of eratic scenarios. At monthly and daily levels major shifts were noted regarding the onset and termination of rains across Bui.The coefficients of variation (CV) for rainfall stood at $12.22 \%$ while that for temperatures was $5.32 \%$ (Table1).

Table 1: Summary statistics on the coefficient of variation for the climatic factors

\begin{tabular}{lccc}
\hline Variable & Mean $\left(\mathrm{x}^{-}\right)$ & $\begin{array}{c}\text { Standard } \\
\text { Deviation(SD) }\end{array}$ & $\begin{array}{c}\text { Coefficient of } \\
\text { Variation(CV) }\end{array}$ \\
Rainfall & 1737.01 & 212.34 & $12.22 \%$ \\
Temperature & 23.3 & 1.24 & $5.23 \%$ \\
\hline
\end{tabular}

Source: Data analysis
From Table1, it can be deduced that both parameters registered significant levels of variability in Bui, hence decreasing levels of reliability. This was corroborated by farmer's views, obtained during field survey, where in, 92\% affirmed the rising frequency of unexpected and extreme weather events in Bui, 5\% stood for realtive stability while $3 \%$ were indifferent.

\section{EFFECT OF TEMPERATURE AND RAINFALL VARIABILITY ON MAIZE PRODUCTION}

\section{1:Correlation between temperature, rainfall and maize yield}

The output and productivity of maize across Bui division show evidence of significant variations over time and space. Maize output is observed to have increased over time but yields have dropped from10.1tons/ha to 6.4tons/ha on average. Rainfall and temperature variability in Bui have some influence on maize yields. The Pearsons' Correlation Coefficient was used to establish the relationship between the variables over a period 2000-2010. Correlation coefficient values ranges from -1.00 to +1.00 . The value of 1.00 represents a perfect negative correlation while a value of +1.00 represents a perfect positive correlation and the value of 0.00 represents the absence of correlation(Table 2). 
International Journal of Environment, Agriculture and Biotechnology, 5(3)

May-Jun, 2020 / Available: https://ijeab.com/

Table 2: Summary of the Pearson's' correlation test results between climate and yield

\begin{tabular}{lccc}
\hline Variable Tested & $\begin{array}{c}\text { Pearson's correlation } \\
\text { coefficient(r) }\end{array}$ & $\begin{array}{c}\text { Coefficient of } \\
\text { Determination(r2) }\end{array}$ & $\begin{array}{c}\text { Proportion of climatic } \\
\text { element in the change }\end{array}$ \\
$\begin{array}{l}\text { Rainfall and Maize } \\
\text { yields }\end{array}$ & 0.56 & 0.31 & $30.85 \%$ \\
$\begin{array}{l}\text { Temperature and Maize } \\
\text { Yields }\end{array}$ & 0.36 & 0.13 & $13.19 \%$ \\
\hline
\end{tabular}

Source: Data analysis

The summary of the Pearson's correlation for the climatic factor and maize yields, is at the 0.05 level of significance (2-tailed test). The analysis of correlation coefficient reveals that rainfall shows a generally moderate positive relationship with yields $(+0.56)$, implying rainfall variations in the area contributed significantly to the decreasing maize yields in the area. The coefficient of determination value of 0.31 , signifies rainfall variation contributed to $30.85 \%$ of the changes in yields. It was also observed that most often rainfall distribution affects maize output and yield more than the rainfall amount itself. Temperature on its part demonstrates a weak positive relationship with yields, shown by a correlation coefficient of $(+0.36)$, implying temperature variations in Bui had just a little to contribute in the varying maize yields within the period. The coefficient of determination of 0.13 implies temperature variation contributes to $13.19 \%$ of maize production change.

Bui division in general is a relatively cold area and rising temperatures in this zone are still very moderate and favourable to the maize plant, by most often providing the Growing Degree units within relatively short periods. It was observed that this positive relationship is usually distorted once extremes are reached or when a certain threshold is exceeded, especially during the germinating, vegetative growth, silking and grain filling stages of the maize plant. Rainfall and temperature variability therefore jointly contribute to $44.04 \%$ of the variation in maize yields over Bui within the reference period, while the remaining 55.96\% is explained by stochastic variables such as improved seeds, application of fertilizers, soil fertility, methods of cultivation and other related factors.

4.2: Modifications and shifts in maize farmers' calendar of activities

ISSN: $2456-1878$

https://dx.doi.org/10.22161/ijeab.53.21
Field survey revealed maize famers calendar of activities across Bui had been highly affected at varying levels across the entire division over the period. The greatest disruptions were observed during and around the planting period (generally known to run for a week or two (MidMarch- early April). The fact that the period most often coincided with the holiday periods for the primary and secondary school pupils, made the task easier for famers thanks to the services of these holiday makers. The rising seasonal instability in the area characterized by major variations in the onset and termination dates for the rainy season, as was the case in 2006, when the rains began unexpectedly during the last week of the month of February. After farmers had planted, a dry spell occurred for a week's period, resulting in the decay of the already planted seeds, especially for those that were soaked in water before planting, leading to a partial replanting of the affected areas. An exercise seen to be very costly to farmers who in majority don't have sufficient food needs year out. In such years, the weeding exercise usually begin early, as the early rains favours rapid generation of weeds, known to survive even under weather conditions considered challenging for maize. The early growth of weeds implies a high possibility of weed regeneration before the maize reaches the grain filling stage, hence a second wedding phase is imposed. Extra labour is needed which if not provided, gives the weeds a chance to compete for nutrients with the maize plant, resulting in poor yields.

4.3: Negative crop response to anomalous events and difficulty in applying farm chemicals

The observed changes in rainfall trends and the seasonal patterns of distribution were observed to have had both a direct and indirect influencing on maize production. Episodes of heavy downpours associated with hail have caused valley floods and severe soil erosion on the hilly 
slopes, especially on the Oku and Djottin slopes. Such was the case in the 2008 and 2009 farming seasons in which floods resulting from torrential downpours destroyed lots of maize plants along the banks of the Mii stream, in the Ngeptang and Bamti farming areas. This affected output negatively in these areas which resulted to an increase in price of corn at both farm and market levels. Effective application of chemical fertilizers, insecticides and pesticides became a major challenge due to the increasing unpredictability of rainfall events. It became very difficult for the farmers to predict a sunny day within the rainy reason, considered favourable for the application of farm chemicals to permit it have an impact on the crop. It is common to see bright sunny day turn into rainy day within unexpected time, and when this happens, the chemicals are washed away without them having a significant effect on the plant yet. This was reported to have been a major challenge to the indigenous weather prediction experts. Field interviews revealed that during the 2001 cropping season in which maize farmers in Mbotseng suffered from moisture stress during the ear-filling stage, a significant drop in output was registered. But at the same time the year 2000 which was a relatively dry year, with low-soil moisture reserves, had sufficient rainfall during the ear-filling stage, which affected maize output positively. The relatively higher temperatures in Mbonso, Lasin, and Ibal-Oku in in the 2009 cropping season, associated with high diurnal variations during the flowering and grain-filling stages saw maize sterility on a rise.

4.4: Minor changes in the growing period and increasing wilting incidence for maize

Comparatively, field reports indicated that there has been a slight shrink in the growing period for maize specifically at the extreme west of the division(Jikejem-oku), where maize was planted early March and harvesting in September, contrary to November harvesting, as was the case in the eighties. This indicated that, the maize plant could now receive the required heat units for growth, maturity and ripening within a shorter period. This had certainly been a consequence of the rising mean temperatures in the area. Wilting of maize plants was highly recurrent especially on steep slopes having shallow soils with relatively low moisture. This reduced plant vigour and lowered maize plant's resistance to nematodes and insects. The effects on maize are more serious during the critical period (thirty to forty days on either sides of flowering). This was noted to be common in Mbam-Oku and in the northern parts of Djottin in Noni, coupled with modest rainfall that enabled weeds to deprive maize of water, particularly during the male and female flowering periods.

\section{5: Proliferation of maize pest, falling farm incomes and livelihood standards for farmers}

The climate related environmental conditions that prevailed as observed earlier, were highly conducive for the breeding and proliferation of pests that affected maize production negatively in the area. These organisms, dominated mostly by weeds, insects and pathogens, reduced maize value at both pre and post-harvest levels. The distribution and proliferation of weeds, fungi and insects in Bui varied with the trends in the key climatic elements. The floods and prolonged rainy season of 1996 that characterized parts of Nkum and Noni were indicated to had favoured the prevalence of leaf fungi and corn smut, increased leaf blight and rust in farms planted with the COCA (a local variety) specie. The dry spell of 2001 and 2004 and 2007 in Lasin and Nkor, favoured the growth of insect vector population, which saw young maize plants invaded by corn leaf beetles, followed by a high degree of stalk borer infestation. Increasing temperatures in Mbancham-Oku gave way to the expansion of leaf beetles to previously unaffected areas, the emergence of weevils at Kevu-Oku, led to a rise in the crickets and maggots, army worms and stalk borers that destroyed maize stems especially during the vegetative period, causing as high as $20 \%$ losses to some farmers. Jakiri Sub division in 2006 and 2008 registered severe dry spells, that affected maize production drastically.

Farmers who cultivated dry season maize in home gardens and in swamps around Tadu, witnessed shortages in irrigation water. The resulting effect was dropping yields for maize, which affected farm and farmers' incomes negatively, in a zone where more than $80 \%$ of the farmers depend on food crop production and marketing of surpluses to purchase basic needs, and at times are unable to purchase planting seeds for the coming season. This obliged them to adjust household food consumption and get into household savings. The resulting fall in livelihood standards most often trigger a labour seeking rural out-migration to destinations mostly in the Littoral and Southwest Regions of Cameroon. The increase application of farm chemicals tends to absorb part of the family income, associated with the growing climate related pests at both the pre and post-harvest levels, at a period when farmers' incomes are shrinking. The falling incomes implies a rising inability for maize farmers to efficiently mitigate or adapt to unfavorable climatic 
scenarios. The exposure of food needs and farm incomes to the impacts of climatic variability in Bui were also perceived by the maize farmers following the Likert scale (Table 3), which registered varying percentages and degrees of impacts.

Table3: Likert indicators showing the magnitude of perceived climatic impacts

\begin{tabular}{lc}
\hline Likert scaling & Proportion \& degree of impact \\
\hline Very severely affected & Above $50 \%$ \\
Highly affected & 30 to $50 \%$ \\
Moderately affected & 10 to $30 \%$ \\
Slightly affected & Less than $10 \%$ \\
\hline
\end{tabular}

Source: Field survey (2018)

From Table3 it can be observed that those who have been very severely affected (above 50\%) are top non the chart, closely followed by the highly affected (30-50\%), the moderately affected (10-30\%), with less than $10 \%$ slightly affected. Focus group discussions and field interviews revealed that majority of the farmers who perceived moderate and slight effects of climate variability on their food needs and incomes, were mostly those supplementing food and income with the consumption and sales from other corps that are planted in a mixed or sole cropping systems such as beans, Irish potatoes and plantains.

\section{ADAPTATION STRATEGIES ADOPTED BY MAIZE FARMERS AT VARYING LEVELS}

Adaptation here implies how maize farmers in Bui are dealing with the consequences of climate variability that cannot be avoided. It involves taking practical actions to protect and strengthen their resilience. This was aimed to moderate or avoid harm while exploiting the beneficial opportunities.

\section{1: Adoption of resistant maize varieties and the role of the} extension service

A few farmers have been experimenting some high yielding maize varieties (COCA, ATP and KASAI species) at a very limited scale. COCA was reported to be the most widely adopted, reason being that it's good for corn-fufu, a staple food in the area and is also more adaptable to the ecology of the area. The ATP was cultivated in low altitude zones with a low frequency of strong winds, added to the fact that it is more resistant to pest attack and also has high yielding potentials. The KASAI specie was adopted mostly by farmers in high altitude zones where violent winds were frequent, since it could not be easily destroyed be wind thanks to its dwarf nature. The extension service of the ministry of agriculture and rural development facilitated the adoption of these new species by disseminating both their seeds and ideas on the techniques of cultivation across Bui. This was through farming groups such as Bonglim in Kitiwum, Tomngeh and Bongsuru both in Kigomin and also amongst church, women empowerment and common initiative groups.

5.2: Changing of planting dates and increase use of fertilizers and pesticides

With the rising unpredictability in rainfall, most farmers became more prudent, and planted only beans after the first rains, reason being that unlike maize, beans do not easily decay in case a dry spell occurs after the first rains. Hence maize is planted only when an acceptable amount of rain has fallen at a minimum of two-days interval for at least a week. They had stopped letting maize seeds absorb water for some few hours before they are planted, since it makes the seeds more susceptible to heat damage in case of unexpected dry circumstances. Farmers had increased the purchase and application of pesticides and chemical fertilizers on their farms. Field studies indicated that the application of pesticides and chemical fertilizers had increased in the division over the period. These have been linked to climate related increases in both pre and postharvest pests. At Manchock-Oku, some farmers were observed integrating maize cultivation with animal raring, which in addition to high level mulching, helped improved soil fertility through composting.

\section{3: Modification of cultivation techniques and the practice} of agro-forestry

Farmers adopted new cultivation methods and techniques in order to minimize the vulnerability level and the degree of impact of extreme events such floods, dry spells, violent rain and wind storms on their activities. The "slash and burn" method of farming and the vertical formation of ridges saw a decrease across Bui over the period, aimed at minimize the rate of erosion resulting from sudden and unreliable heavy downpours noted to have been common in Bui. Contour farming was increasingly practiced to replace the vertical ridges on steep slopes, as more than $50 \%$ of farms in the division are on high gradient zones while terracing became common on the slopes of mount Oku (northern parts of Mboh and Kesotin). Some farmers 
switched to mixed-cropping while others moved from simultaneous inter-cropping to a relay inter- cropping system, which became an effective means of ensuring at least some harvest in seasons with multiple climatic vagaries. Planting of plantains, pears and mangoes on farms originally destined only for maize and other cereals became common in areas like Goff in Djottin(Noni), Mboh and Ichim(Oku). These tree crops have the potential of surviving in different seasonal conditions, so they played an important role in reducing the risk of complete crop failure and also play a great role in carbon sequestration, increase interception and infiltration rates while preventing rapid overland flow and high rate of soil erosion.

\section{4: Using Indigenous Knowledge to predict weather conditions}

The absence of updates on weather forecast obliges farmers to rely on traditional indigenous knowledge in order to survive in a more variable climate. Focus group discussions with the farmers revealed the use of indicators such as, the nesting behaviour and migration pattern of birds, incidences of certain insects, the flowering of some specific trees, direction of migration of honey bees, the appearance of rare bird species. The persistent cry of certain birds in the early hours of the morning predicts heavy rain showers during that day, the development of scars on the ground, around the month of October depicts early approach of the dry season, shedding of leaves by trees such as the fig tree, indicate the approach of the dry season. Some farmers even believe that offering libations to ancestral gods can help prevent meteorological extremes. Table4 present farmers' adaptation strategies.

Table4: Key adaptation strategies adopted by maize farmers of Bui

\begin{tabular}{|c|c|c|}
\hline Adaptation Levels & Frequency & \% Frequency \\
\hline \multicolumn{3}{|c|}{ Plant level adaptation } \\
\hline Crop diversification & 153 & $85.22 \%$ \\
\hline Improved crop varieties & 57 & $31.66 \%$ \\
\hline \multicolumn{3}{|c|}{ Farm level adaptation } \\
\hline Increase use of fertilizers & 164 & $91.21 \%$ \\
\hline Practice of agroforestry & 58 & $32.22 \%$ \\
\hline Farm diversification & 77 & $42.89 \%$ \\
\hline Modifying cropping methods & 114 & $63.27 \%$ \\
\hline \multicolumn{3}{|c|}{ Farmer's level adaptation } \\
\hline Change of planting dates & 129 & $71.93 \%$ \\
\hline Use of Indigenous knowledge & 161 & $89.36 \%$ \\
\hline Adjusting periods of pesticide application & 50 & $27.85 \%$ \\
\hline
\end{tabular}

Source: Field survey (2018)

\section{CONSTRAINTS TO FARMERS' ADAPTATION PROCESS}

These are those elements that farmers observed to have made it harder for them to either plan and or implement adaptation actions. The results of the Focus Group Discussions, direct field observation and interviews confirmed that the high unpredictability of weather events, lack of timely meteorological information, high and increased cost of related farm inputs make effective planning completely difficult amongst farmers. The absence of agricultural loans hinders farmers from acquiring useful material for even mitigation, especially agrochemicals, while the inadequate number of agricultural extension officers, slows down the dissemination of information on sustainable adaptation options. Frequent inter-tribal conflicts, like was the case between Oku and the Mbesa tribes in 2008, between the Nso and Djottin tribes in 1992 and between Din and Oku in 1997 and 1999 create an unconducive atmosphere for effective adaptation. FGDs revealed that the conflict hot spots have all been very fertile areas for good maize harvest 
(Balu for Oku and Noni, Koh-embeh for Mbessa and Oku and Mbiim for Nso and Djottin). These conflicts affect the entire livelihoods of maize farmers, who spend the little income they have to rebuild the damage instead of purchasing fertilizers and other farm inputs. Farmer-grazier conflicts noted to be recurrent in Noni and Mbven sub divisions also constrain farmers' adaptation to climate variability, through crop destruction and its negative effects on output and farmers' income. Lack of efficient storage facilities obliges most farmers to sell a greater portion of their produce for fear of weevil related post-harvest losses. This is usually at extremely low prices, compared to the cost of the seeds during the planting period. This brings negative shifts in both farm incomes and farmers livelihoods, making the planning and implementation of adaptation difficult.

\section{DISCUSSION}

The results of this study indicates that there had been a slight drop in annual rainfall amount over time, delays in the onset and termination of the rainy season, frequent dry spells, erratic rainfall events and highly varying rainfall intensity and decreasing rainy days in Bui over the study period, temperature show a moderate rising trend over the period. Similar results were presented by Stanturf et al, (2011), who concluded that increasing incidence of dry spells, floods, decreasing annual precipitation and rising temperatures in the Northern Region, Ghana had become a major concern. It also corroborates the results of Amawa et al, (2015), who presented visible evidence on the high variability of both temperature and rainfall in Santa, Cameroon. It is also line with the findings of Yamba et al (2019), who reported that rainfall amount for the Ghanaian district of Bosomtwe had decreased and become inconsistent in recent decades. It also corroborates with the conclusions of Getamesay, B. D., \& Kifle H.B., (2019), that both annual, average and minimum temperatures had increased in the Sekota District of Ethiopia over the decades while annual precipitation had been on a decrease over the last 30years. However, the varied topography in Bui division, composed both highly elevated zones like Oku and lowland areas like wassi-Ber and Lasin has made the variations in temperature and rainfall pattern to be heterogeneous and consequently affecting maize production differently.

Regarding the effects on maize production, the results revealed that rainfall variability, especially its distribution affected maize yields negatively while mean temperature had a slight favourable effect on maize yields, with its anomalous situations affecting maize negatively. The transferred effects have been shifts in farmers' calendar of activities, negative crop response to anomalous events and minor changes in the growing period, increasing wilting incidence for maize, maize pest proliferation, falling farm incomes and livelihood standards for farmers. Similar results have also been reported by Ndamani F. \& Watanabe T (2016), Okeyo B \& Wamugi S.M, (2018), which also go together with the findings of Mulungu, $\mathrm{K} \& \mathrm{Ng}$ 'ombe, J.N, (2019) that climate change threatens productivity and production of maize, due to its high dependence on water availability. Despite this similarity, Bui is unique as rising temperature trends seems favourable for maize production due to its dominantly elevated topography that moderates the diurnal temperature.

The results on adaptation indicates that, the key adopted strategies included, adoption of resistant maize varieties, changing of planting dates, increase use of fertilizers and pesticides, modification of cultivation techniques, the practice of agro-forestry and the usage of indigenous knowledge. Related results have been reported in the Ndop plain in Cameroon, where rice farmers have been able to use knowledge of weather systems such as rains, thunderstorms, and sunshine to prepare for future weather, Moye, (2018). The results also support the conclusions of Ndaki (2014), that smallholder farmers will adopt new crop varieties, as a way of adapting to the effects of the changing climatic trends. The results further revealed these strategies remained inefficient due to challenges such as the lack of timely meteorological information, absence of agricultural loans, inadequate extension service, lack of efficient storage facilities, and local conflicts. A similar observation was made in the Mazungunye community, in Zimbabwe by Nyahunda, L.\& Tirivangasi, H.M. (2019), who reported that lack of resources and techno science adaptive methods, were major challenges in adapting to the effects of climate change on the farming community. The difference with Bui maize farmers is that some are taking advantage of the temperature induced reduction in the growing period for maize by harvesting early and using the space for the cultivation of second cycle beans, when the rains are still enough to guarantee a good harvest.

\section{CONCLUSION}


The objectives of this paper were to; (1) ascertain whether there has been any variability in temperature and rainfall in Bui Division between 1991 and 2010, (2) evaluate the effects of temperature and rainfall variability on maize production, (3) examine the strategies put in place by maize farmers to adapt to the negative effects of climate variability. Findings show that there had been a slight drop in annual rainfall amount over time, delays in the onset and termination of the rainy season, frequent dry spells, erratic rainfall events and highly varying rainfall intensity with decreasing rainy days while temperature show a moderate rising trend over the period. The varying trends in temperature and rainfall were observed to have partly contributed to a decrease in maize yields over time, affecting farmers' incomes negatively. The farmers have been putting in place copping strategies such as crop diversification, practice of agroforestry, farm diversification, modification of cropping methods and change of planting dates. These strategies remain inefficient due challenges like absence of weather prediction, inadequate finances and farm inputs. To address the situation, more efficient meteorological systems through which information on weather predictions will be disseminated to farmers through their mobile sets. More extension officers should be trained and deployed on the field, organize agricultural workshops to help build farmers' capacity on the best adaptation options. The state can provide low or zero interest agricultural loans. Youths need to be encouraged in agriculture since they have the defining attributes when it comes to utilizing modern agricultural techniques. They are well connected through electronic devices that can help modernize maize farming, share adequate and regular information on key issues linked to the effect of climate variability on agriculture and maize production in particular. If these measures are effectively put in place, they will not only help improve on maize production and productivity in Bui but will also go ahead to guarantee food security while checking against rural exodus in the region.

\section{REFERENCES}

[1] Amawa, S.G, Kimengsi J.N, Tata E.S, \& Azieh E. A, (2015): The Implications of Climate Variability on Market Gardening in Santa Sub-Division, North West Region of Cameroon. Environment and Natural Resources Research; Vol. 5, No. 2; 2015 ISSN 1927-0488 E-ISSN 1927-0496. Accessed at: http://dx.doi.org/10.5539/enrr. v5n2p14

[2] Bendell, J. (2018): Deep Adaptation: A map for navigating climate tragedy, IFLAS Occasional Paper2.
Retrieved at https://www.lifeworth.com/deepadaptation.pdf

[3] Getamesay, B. D., \& Kifle H.B., (2019): Climate and Variability: Farmers' perceptions in Sekota district, Northeastern Ethiopia, SN - 978-3-330-07219-0. Lap Lambert Academic Publishing; Saarbrücken, Germany. Accessed at: http://localhost:80/xmlui/handle/123456789/15136

[4] Godwill, T.N., Kiming, I.N., Nyuyki, B.B, Akoni, I.N., George, N.D., (2020): Challenges of Rural Landscape Mosaic and Beautification in Oku, North West Region of Cameroon. International Journal of Science and Qualitative Analysis. Vol. 6, No. 1, 2020, pp. 1-7. doi: 10.11648/j.ijsqa.20200601.11

[5] Henstra, D. \& Mcbean.G. (2009): Making Canada's Communities More Resilient to the Impacts of Climate Change and Extreme Weather, Summary Recommendations, p2-5

[6] IPCC (Intergovernmental Panel on Climate Change). (2015). Fifth Assessment Report; Climate Change 2014: Impacts, Adaptation, and Vulnerability in Rural Areas.https://ipccwg2.gov/AR5/images.Accesse. Retrieved 16/08/2015

[7] IFPRI, (2009): Agricultural Adaptation to Climate Change in the Developing World: Policy Seminar 5th October 2009 Washington DC

[8] Kiming, I.N, Moye, E.K, Jude, K, (2020). Mountain Apiculture and Environmental Dynamics: Impact of Climate Variability on Bee Farming in OKU, Cameroon. International Journal of Environmental, Sustainability, and Social Science, 1(1), 77-87. https://doi.org/10.38142/ijesss.v1i1.52.

[9] Maidment, R, D, Grimes, R. P. Allan, E. Tarnavsky, M. Stringer, T. Hewison, R. Roebeling and E. Black (2014): The 30 years TAMSAT African Rainfall Climatology and time series (TARCAT) data set. Journal of Geophysical Research. DOI: $10.1002 / 2014 J D 021927$

[10] Moye, E.K, (2018): The implications of climate variability on the livelihoods of rice crop farmers of the Ndop Plain, Northwest Region of Cameroon. PhD thesis University of Dschang 389p

[11] Munang, R, Rivington, M \& Colls, J., (2008): Climate variability and maize production in Cameroon: Simulating the effects of extreme dry and wet years. Singapore Journal of Tropical Geography, Volume 29, P357-370. doi 10.1111/j.1467-9493.2008. 00344.x

[12] Mulungu, K \& Ng'ombe, J.N, (2019): Climate Change Impacts on Sustainable Maize Production in Sub-Saharan Africa: A Review, Maize - Production and Use, Akbar Hossain, IntechOpen, DOI: 10.5772/intechopen.90033. Available from: https://www.intechopen.com

[13] Mbiydzenyuy (2007): Spacio-Temporal Maize Price Variability in some Markets of the Western Highlands of Cameroon. Unpublished Msc Thesis Faculty of Economics and Management, University of Dschang

[14] Munang, R \& Rivington, M, (2009): Adaptation for crop agriculture to climate change in Cameroon: Turning on the heat..Journal of Mitigation and Adaptation Strategies for Global Change, Volume14, P153-168. doi - 
[15] Nangamo, E and Sonja, V. (2008): Climate Resilience at Africa's grassroots: International Institute for Environment and Development (IIED), Malawi. Accessed at www.iied.org

[16] Ngakfumbe, S.N. (2000): Rainfall Variability over Cameroon: A study of the Characteristics of Rainfall variability in a Tropical Environment; The Geographer (Cameroon), July 200, Vol. I.

[17] Ndamani, F. \& Watanabe, T (2016): Determinants of farmers' adaptation to climate change: A micro level analysis in Ghana. Accessed at http://www.scielo.br/scielo

Ndaki, P.M., (2014) : Climate Change Adaptation for Smallholder Farmers in Rural Communities : the Case of Mkomazi SubCatchment, Tanzania. PhD thesis, University of Oldenburg, Germany. Acessed at www.researchgate.net

[19] Nyahunda, L. \& Tirivangasi, H.M., (2019) : Challenges faced by rural people in mitigating the affects of climate Change in the Mazungunye communal lands, Zimbabwe', Jàmbá : Journal of Disaster Risk Studies 11(1), a596. https://doi.org/10.4102/jamba.v11i1.596Copyright

[20] Norwegian Agency for Development Cooperation (NORAD, 2007): Climate Change adaptation and Poverty Reduction: Key Interactions and Critical Measures. Oslo.

[21] Okeyo, B \& Wamugi, S.M, (2018): Climate Change Effects and the Resulting Adaptation Strategies of Smallholder Farmers in Three Different Ecological Zones (Kilifi, Embu and Budalangi) in Kenya. Journal of Environment and Earth Science, www.iiste.org ISSN 2224-3216 (Paper) ISSN 22250948 (Online) Vol.8, No.7, 2018

[22] Ringler, C. (2008): How can African Agriculture Adapt to climate Change: Results and Conclusions for Ethiopia and beyond. $14^{\text {th }}$ Nov. 2008, Nazareth, Ethiopia. P2-27.

[23] Sadiq, M.A, Kuwornu,J.k, Ramatu M.A, \& Suhiyini I.A, (2019): "Assessing Maize Farmers' Adaptation Strategies to Climate Change and Variability in Ghana," Agriculture, MDPI, Open Access Journal, vol. 9(5), pages 1-17, April. Doi.10.1007/s11027-008-9156-3

[24] Stanturf, A.J, Warren Jr, M.L, Charnley, S, Polasky, S.C, Goodrick, S.L, Armah, F, Nyako, Y.A, (2011): Ghana climate change vulnerability and adaptation assessment. Available at: http://www.encapafrica.org/documents/biofor/Climate\%20 Change $\% 20$

[25] Tsalefac, M. (1999): Variabilité climatique crise économique et dynamisme des milieux agraires sur les Hautes Terres de l'ouest Cameroun. Thèse de Doctorat d'Etat, Spécialité géographie physique option climatologie. Universite de Yaoundé I.

[26] Taku J.D, Amungwa F.A, Manu. I, (2017): Role of Agricultural Extension in Climate Change Adaptation in Cameroon. International journal of Horticulture, Agriculture and Food science(IJHAF) [Vol-1, Issue-3, Sep-Oct, 2017] https://dx.doi.org/10.22161/ijhaf.1.3.5, ISSN: 2456-8635
[27] Tambawal, U.A, (2009): Global Warming and the Millennium Development Goals in Nigeria: A way forward. Usmanu Danfodiyo University, Sokoto, Nigeria.

[28] Tsalefac, M. (2008): Climate Change and Adaptation Metrics: Agriculture and Water Sector: University of Yaoundé.

[29] Tarnavsky, E. D, Grimes, R. Maidment, E. Black, R. Allan, M. Stringer, R. Chadwick, F. Kayitakire (2014): Extension of the TAMSAT Satellite-based Rainfall Monitoring over Africa, from 1983 to present. Journal of Applied Meteorology and Climate. DOI: 10.1175/JAMC-D-14-0016.

[30] Yamba, S, Divine, O.A, Lawrencia P.S \& Sandra R.C, (2019): Smallholder farmers' perceptions and adaptive response to climate variability and climate change in southern rural Ghana, Cogent Social Sciences, 5:1, 1646626 